\title{
Avaliação da Soldabilidade do Aço Sincron EN 10025-4 S355M Aplicado na Fabricação de Torres Eólicas com Processo de Soldagem de Alta Deposição ${ }^{a}$
}

\author{
Tadeu Messias Donizete Borba르, Rodrigo Sanches Oliveira², Hugo Reis Gama², Marília Faria de Oliveira Caizer ${ }^{1}$, \\ Leonardo de Oliveira Turani ${ }^{3}$ \\ 1 Usinas Siderurgicas de Minas Gerais S.A - USIMINAS, Centro de Pesquisa \& Desenvolvimento, Ipatinga, MG, Brasil. \\ 2 Elektriska Svetsnings Aktie Bolaget - ESAB, Assistência Técnica, Contagem, MG, Brasil. \\ 3 Usinas Siderurgicas de Minas Gerais S.A - USIMINAS, Assistência Técnica, Belo Horizonte, MG, Brasil.
}

Recebido: 16 Nov., 2017

Aceito: 25 Jan., 2018

E-mail: tadeu.borba@usiminas.com (TMDB) a Trabalho apresentado no XLIII CONSOLDA Congresso Nacional de Soldagem, 06 a 09 de Novembro de 2017 Joinville-SC, Brasil.

Este é um artigo publicado em acesso aberto (Open Access) sob a licença Creative Commons Attribution Non-Commercial, que permite uso, distribuição e reproduçãa em qualquer meio, sem restrições desde que sem fins comerciais e que trabalho original seja corretamente citado.
Resumo: A busca de soluções em melhoria da produtividade tem sido a tônica nas relações entre a siderurgia e os fabricantes de torres eólicas. Nesse sentido, a Usiminas, após a implantação da tecnologia CLC (Continuous on-Line Control), tem realizado diversos projetos de desenvolvimento de produtos e aplicação dos aços estruturais TMCP (Thermo-Mechanical-Control-Process) com características mecânicas e metalúrgicas diferenciadas em relação aos aços convencionalmente utilizados pela indústria brasileira, em especial pelos fabricantes de torres eólicas. Devido à importância que os processos de soldagem representam na fabricação de torres eólicas, estudos de soldabilidade são importantes para a elaboração de procedimentos e a seleção adequada dos aços e consumíveis que permitam o aperfeiçoamento das etapas de soldagem. Nesse contexto, este trabalho visou avaliar comparativamente as propriedades mecânicas e a caracterização microestrutural da região soldada do aço Sincron EN 10025-4 S355M, produzido pelo processo TMCP, e ASTM A572 grau 50, produzido por laminação convencional, ambos soldados pelo processo SAW Tandem Arc, empregando aportes de calor superiores aos comumente utilizados na soldagem convencional dos tramos metálicos. De acordo com os resultados obtidos, foi possível obter juntas soldadas SAW Tandem Arc com excelentes propriedades mecânicas e tenacidade, especialmente quando empregado o aço Sincron EN 10025-4 S355M, em conjunto com a combinação arame/fluxo OK Autrod12.22/OK Flux 10.72. Os procedimentos de soldagem avaliados neste trabalho podem ser uma excelente referência para o aumento da produtividade na fabricação de torres eólicas, com a redução de passes nas soldas longitudinal e circunferencial das virolas.

Palavras-chave: Aço TMCP; SAW tandem arc; Energia eólica; Zona afetada pelo calor; EBSD.

\section{Weldability Evaluation of Sincron EN 10025-4 S355M Steel Applied in Wind Tower Manufacturing Welding with High Efficiency Process}

\begin{abstract}
The search for solutions to improve productivity has been the emphasis in relations between the steel industry and the wind tower manufacturers. In this sense, Usiminas, after the implementation of CLC technology (Continuous On-Line Control), has conducted several development projects and implementation of structural steel TMCP (Thermo-Mechanical-Control-Process) with mechanical and metallurgical characteristics differentiated in relation to steels conventionally used by Brazilian industry, especially the wind tower manufacturers. Because of the importance of the welding processes in the manufacture of wind towers, weldability studies are important for the development of procedures and the proper selection of steels and consumables enabling the improvement of welding activities. In this context, this work has the objective of comparative evaluate the weldability of steel Sincron EN 10025-4 S355M (TMCP steels) and ASTM A572 grade 50 (Normalizing steels), when welded by SAW Tandem Arc process using heat inputs higher than those commonly used in wind turbine manufacturing. The results obtained showed that is possible to obtain SAW Tandem Arc welded joints with excellent results for mechanical properties and toughness when employed especially Sincron EN 10025-4 S355M steel, together with combination wire/flux OK Autrod12.22/OK Flux 10.72. The welding procedures evaluated in this work can be an excellent way to increase the productivity in the manufacture of wind towers decreasing the number of pass in longitudinal and circumferential welds.
\end{abstract}

Key-words: TMCP Steel; SAW tandem arc; Wind power; Heat affected zone; EBSD. 


\section{Introdução}

A geração de energia elétrica através da conversão da energia cinética dos ventos (energia eólica) é uma tecnologia muito utilizada por diversos países por necessitar de baixos investimentos para implantação e para manutenção em relação às usinas hidrelétricas e nucleares, e por ser uma fonte de geração renovável e limpa, independente da utilização de combustíveis fósseis.

Impulsionado por incentivos federais, com destaque para o pioneirismo do PROINFA (Programa de Incentivo às Fontes Alternativas de Energia Elétrica) [1], o Brasil só começou a explorar essa forma de geração de energia, de forma expressiva, a partir de 2009, principalmente devido à redução dos níveis dos reservatórios hídricos ocorridos nos últimos anos. A partir desse período, a energia eólica tem experimentado um exponencial e virtuoso crescimento no Brasil. Segundo a ABEEOLICA (Associação Brasileira de Energia Eólica) [2], atualmente o Brasil possui em operação 400 usinas com mais de 5 mil aerogeradores e uma capacidade instalada para a geração de 9,4 GW/ano, representando 7\% da matriz energética brasileira. A maior geração de energia eólica se concentra nas regiões Nordeste e Sul, sendo o Rio Grande do Norte, Bahia, Ceará e Rio Grande do Sul os estados com maior capacidade instalada, Figura 1(a).

Para os próximos 2 anos, estão previstos mais de 7 bilhões de dólares em investimentos para o desenvolvimento de mais 175 parques eólicos. Estima-se que o Brasil se torne, até 2020, o sexto maior produtor de energia eólica do mundo, ficando atrás da China, EUA, Alemanha, Índia e Espanha [2].

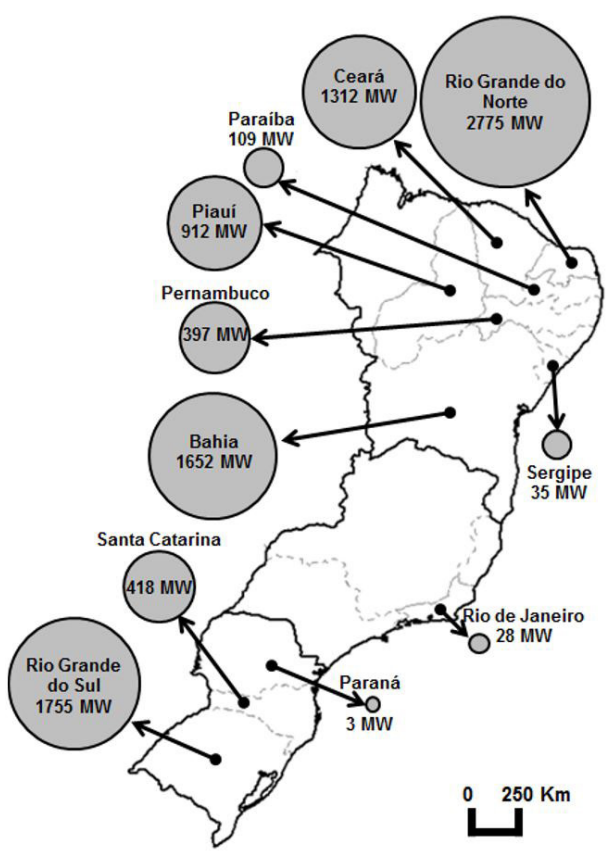

(a) Mapa do setor eólico brasileiro.

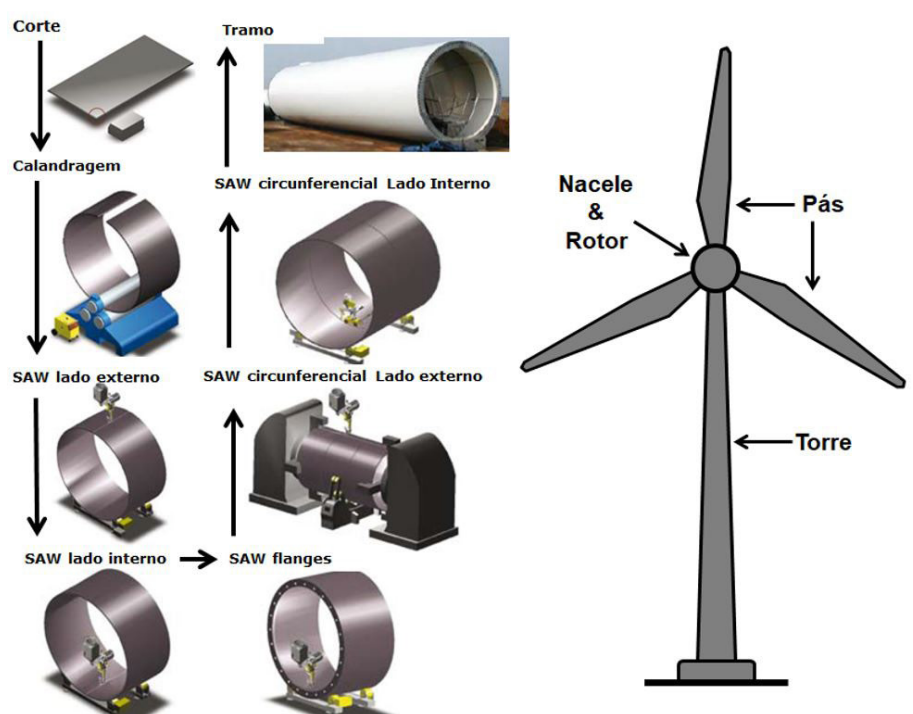

(b) Principais etapas de fabricação de um tramo metálico.

Figura 1. Mapa do setor eólico brasileiro até 2016 (a) e ilustração de um aerogerador e das principais etapas da fabricação de um tramo para torres eólicas (b). Adaptação PROINFA [1] e ESAB [3].

Apesar dos grandes investimentos e incentivos para o desenvolvimento do setor eólico nacional, ainda existe uma grande necessidade de desenvolvimento nas diversas temáticas do setor, principalmente na tecnologia de fabricação de aerogeradores e de materiais, em busca de melhor desempenho de fabricação. No Brasil, mais de $60 \%$ dos investimentos de um parque eólico são destinados à fabricação dos aerogeradores [4], sendo de 20 a $25 \%$ deste custo destinado à construção das torres [4], que são na grande maioria do tipo cônicas de aço, podendo utilizar, dependendo de sua altura, de 100 a 200 ton. de aço para a sua construção.

Torres de aço cônicas envolvem basicamente operações de caldeiraria e corte das chapas, dobramento e várias operações de soldagem. As torres são produzidas em 3 ou 4 segmentos, denominados seções ou tramos. 
Avaliação da Soldabilidade do Aço Sincron EN 10025-4 S355M Aplicado na Fabricação de Torres Eólicas com

Processo de Soldagem de Alta Deposição

Cada tramo é produzido pela união de, geralmente, 5 a 6 virolas de aproximadamente 3 metros de comprimento cada. Tanto para a soldagem longitudinal, utilizada na fabricação das virolas, quanto para a soldagem circunferencial, aplicada na união entre virolas, é utilizado o processo de soldagem a arco submerso (SAW), Figura 1(b).

Dessa forma, a Usiminas e a ESAB, vêm realizando estudos para o desenvolvimento da engenharia de aplicação de aços e consumíveis para o mercado eólico, otimizando as várias etapas da fabricação dos tramos metálicos e melhorando a produtividade da fabricação dessas estruturas metálicas. Nesse contexto, este trabalho visou avaliar o desempenho dos aços estruturais S355M e ASTM A572 grau 50, de $40 \mathrm{~mm}$ e $38 \mathrm{~mm}$ de espessura, respectivamente, quando soldados pelo processo SAW com a adição de dois arames energizados (SAW Tandem Arc) empregando aportes de calor superiores aos comumente utilizados na soldagem convencional dos tramos metálicos.

\section{Materiais e Métodos}

\subsection{Materiais}

Neste estudo, foram avaliados como metal base (MB) os aços estruturais processados em escala industrial: (i) (Sincron S355 M): material que atende os requisitos da norma EN-10025-4 S355 M produzido via laminação controlada seguida de resfriamento acelerado (Thermo Mechanically Controlled Processed - TMCP) e; (ii) (A572): material que atende os requisitos da norma ASTM A572 grau 50 produzido por laminação convencional seguido de tratamento térmico de normalização. A composição química realizada via espectroscopia ótica, o aspecto microestrutural após ataque com reativo nital 4\%, e as propriedades mecânicas desses materiais se encontram na Tabela 1, Figura 2, e Tabela 2, respectivamente.

Tabela 1. Composição química dos aços Sincron EN-10025-4 S355 M e ASTM A572 grau 50 (\% p/p).

\begin{tabular}{|c|c|c|c|c|c|c|}
\hline Aço & C & Mn & Si & $\mathbf{P}$ & $\mathbf{S}$ & Al \\
\hline Sincron S355 M & 0,08 & 1,51 & 0,24 & 0,012 & 0,002 & 0,042 \\
\hline \multirow[t]{2}{*}{ A572 } & 0,17 & 1,46 & 0,34 & 0,022 & 0,008 & 0,033 \\
\hline & $\mathrm{Ca}$ & $\mathbf{N}$ & \multicolumn{2}{|c|}{$\mathrm{Cu}+\mathrm{Ni}+\mathrm{Cr}$} & $\mathrm{Nb}+\mathrm{V}+\mathrm{Ti}$ & Ceq $^{a}$ \\
\hline Sincron S355 M & 0,0015 & 0,0052 & \multicolumn{2}{|c|}{0,050} & 0,031 & 0,34 \\
\hline A572 & 0,0010 & 0,0030 & \multicolumn{2}{|c|}{0,039} & 0,059 & 0,42 \\
\hline
\end{tabular}

${ }^{\mathrm{a}} \mathrm{Ceq}=\mathrm{C}+\mathrm{Mn} / 6+(\mathrm{Ni}+\mathrm{Cu}) / 15+(\mathrm{Cr}+\mathrm{Mo}+\mathrm{V}) / 5[5]$

Tabela 2. Valores de propriedades mecânicas determinados em tração dos aços Sincron EN-10025-4 S355 M e ASTM A572 grau 50.

\begin{tabular}{|c|c|c|c|}
\hline Aço & Limite de Escoamento (MPa) & Limite de Resistência (MPa) & Alongamento $(\%)^{b}$ \\
\hline Sincron S355 M & $451 \pm 11$ & $534 \pm 11$ & $30 \pm 2$ \\
\hline Especificação & $\geq 345$ & $470-630$ & $\geq 21$ \\
\hline A572 & $430 \pm 9$ & $563 \pm 9$ & $23 \pm 4$ \\
\hline Especificação & $\geq 345$ & $\geq 450$ & $\geq 21$ \\
\hline
\end{tabular}

valor médio determinado a partir do ensaio de três corpos de prova. ${ }^{\mathrm{b}}$ Base de Medida $=50 \mathrm{~mm}$.

As microestruturas características dos aços Sincron S355 M e A572 podem ser observadas na Figura 2. O aço A572 apresenta um bandeamento microestrutural de ferrita poligonal e perlita. No caso do aço Sincron S355 M, percebe-se a presença, em maior quantidade, de bainita e, em menor quantidade, de ferrita poligonal e finos nódulos de perlita, bem mais refinadas do que os constituintes observados no aço A572.

O refinamento microestrutural do aço Sincron S355 M pode ser atribuído ao efeito combinado dos parâmetros de laminação controlada e do resfriamento acelerado que, associados à composição química, afetam significativamente os produtos de transformação da austenita. Como já demonstrado em diversos trabalhos [6-8], esse refinamento estrutural proporciona uma excelente combinação de resistência mecânica com elevados valores de tenacidade. 


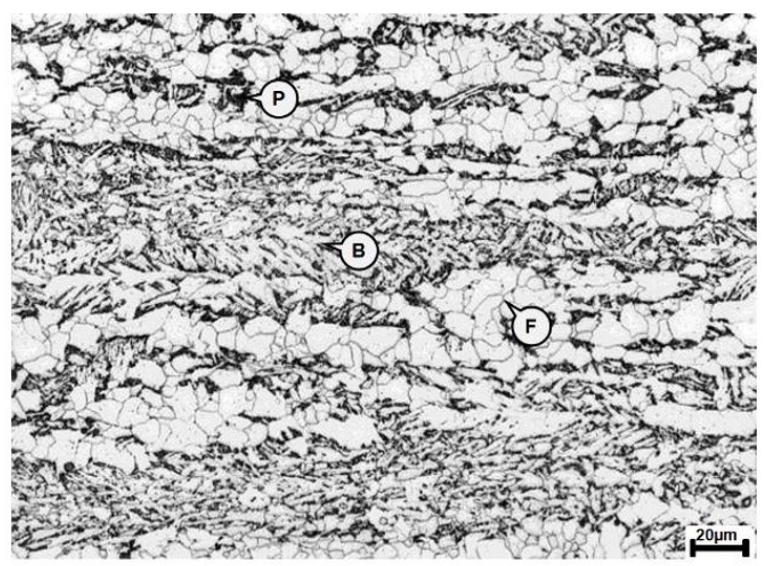

(a) Sincron EN 10025 - S355 M.

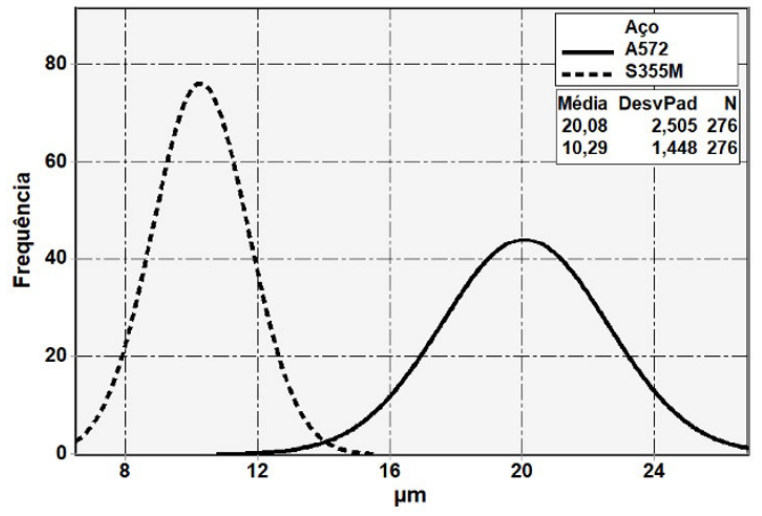

(c) Distribuição do tamanho de grão ferrítico.

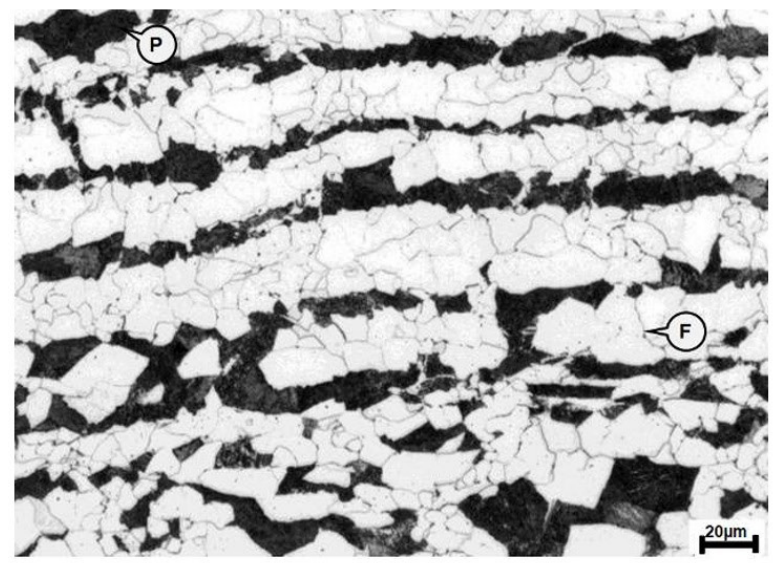

(b) ASTM A572 grau 50.

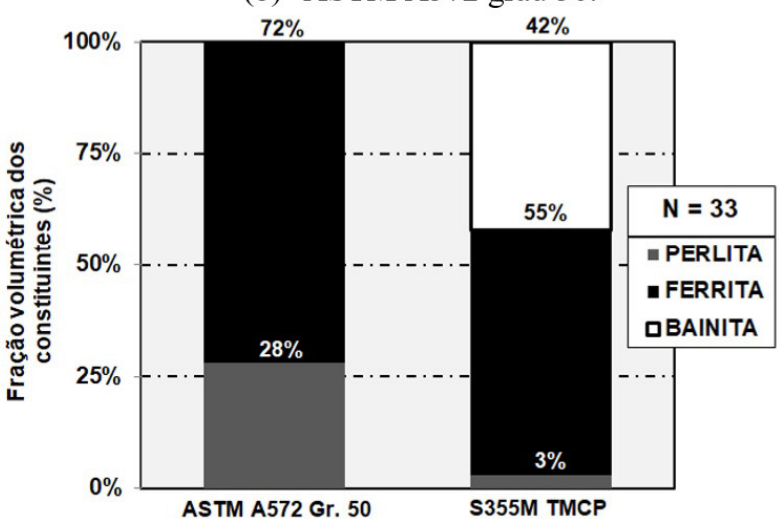

(d) Fração volumétrica dos constituintes.

Figura 2. Microestrutura (a e b), distribuição do tamanho de grão ferrítico (c) e fração volumétrica dos constituintes microestruturais dos metais base avaliados (d). Ataque: Nital $4 \%$.

\subsection{Confecção e caracterização das juntas soldadas}

As informações típicas dos consumíveis empregados na soldagem estão apresentadas na Tabela 3. Como metal de adição, foi usada a combinação fluxo e eletrodo segundo a classe AWS A5.17 - F7A8-EM12K de 5,0 mm de diâmetro. O fluxo empregado foi especialmente desenvolvido para a soldagem de torre eólica e é do tipo aglomerado neutro/básico, que possibilita a deposição de um metal de elevada tenacidade a baixas temperaturas. Para a soldagem das duas amostras, foi utilizado um chanfro simétrico, duplo V, com ângulo de $80^{\circ}$ e $5 \mathrm{~mm}$ de nariz. Nas duas juntas, foi realizado um passe de selagem empregando o processo de soldagem MAG (Metal Active Gas) com consumível de 1,2 mm de diâmetro AWS SFA 5.18 ER70S-6. Não foi utilizado preaquecimento e a temperatura entre passes foi mantida abaixo de $250^{\circ} \mathrm{C}$.

Tabela 3. Composição química e valores de propriedades mecânicas típicos dos consumíveis utilizados [9].

\begin{tabular}{ccccccccc}
\hline Comercial & Classe AWS & C & Si & Mn & $\begin{array}{c}\text { LE } \\
(\mathbf{M P a})\end{array}$ & $\begin{array}{c}\text { LR } \\
(\mathbf{M P a})\end{array}$ & $\begin{array}{c}\text { AL } \\
(\%)\end{array}$ & $\begin{array}{c}\text { CVN } \\
(\mathbf{J})\end{array}$ \\
$\begin{array}{ccccccc}\text { Ok Autrod 12.51 (selagem) } \\
\begin{array}{c}\text { OK Autrod 12.22 (eletrodo) } \\
\text { OK Flux 10.72 (fluxo) }\end{array}\end{array}$ & ER70S-6 & 0,8 & 0,90 & 1,50 & 470 & 560 & 25 & $70\left(-20^{\circ}\right)$ \\
\hline
\end{tabular}

Gás $\mathrm{Ar}+20 \% \mathrm{CO}_{2}$.

Para aperfeiçoar as etapas de soldagem utilizadas na fabricação dos tramos metálicos foi proposta a alteração do procedimento de soldagem, de forma a reduzir o número de passes de solda depositados. Para isso, foi confeccionada, para cada tipo de aço, uma junta soldada pelo processo SAW Tandem arc empregando aporte 
Avaliação da Soldabilidade do Aço Sincron EN 10025-4 S355M Aplicado na Fabricação de Torres É́licas com Processo de Soldagem de Alta Deposição

de calor superior aos comumente utilizados pelos fabricantes de torres eólicas. Os parâmetros de soldagem utilizados neste trabalho estão apresentados na Tabela 4 (Tandem arc procedimento otimizado) onde também é apresentado, apenas como informação, o procedimento de soldagem convencional (Tandem arc procedimento convencional) que não foi avaliado nesse estudo.

Tabela 4. Parâmetros de soldagem Tandem Arc, procedimentos convencional e otimizado.

\begin{tabular}{|c|c|c|c|c|c|c|c|c|}
\hline & $\begin{array}{l}\text { Lado do } \\
\text { Chanfro }\end{array}$ & Passe & $\begin{array}{l}\text { Corrente } \\
\text { (A) }\end{array}$ & $\begin{array}{c}\text { Tensão } \\
\text { (V) }\end{array}$ & $\begin{array}{c}\text { Velocidade } \\
\text { (cm/min) }\end{array}$ & $\begin{array}{c}\text { Aporte de } \\
\text { Calor }(\mathbf{k J} / \mathrm{cm})\end{array}$ & $\begin{array}{c}\text { Deposição } \\
\text { (kg/h) }\end{array}$ & Geometria do Chanfro \\
\hline \multirow{10}{*}{ 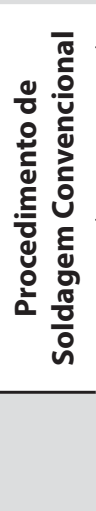 } & \multicolumn{2}{|c|}{ Selagem MAG } & 270 & 27 & 40 & 12 & \multirow{5}{*}{20,3} & \\
\hline & \multirow{4}{*}{ Externo } & \multirow{2}{*}{$1^{\circ}$} & $800^{\mathrm{a}}$ & $34^{\mathrm{a}}$ & \multirow{2}{*}{75} & \multirow{2}{*}{42} & & \\
\hline & & & $700^{b}$ & $36^{b}$ & & & & Externo \\
\hline & & \multirow{2}{*}{$2^{\circ}-5^{\circ}$} & $750^{\mathrm{a}}$ & $34^{a}$ & \multirow{2}{*}{75} & \multirow{2}{*}{41} & & \\
\hline & & & $720^{b}$ & $35^{b}$ & & & & \\
\hline & \multirow{4}{*}{ Interno } & \multirow{2}{*}{$1^{\circ}$} & $900^{a}$ & $33^{a}$ & \multirow{2}{*}{50} & \multirow{2}{*}{60} & \multirow{4}{*}{21,2} & \\
\hline & & & $580^{\mathrm{b}}$ & $35^{b}$ & & & & Intern \\
\hline & & \multirow{2}{*}{$2^{\circ}-4^{\circ}$} & $750^{\mathrm{a}}$ & $34^{a}$ & \multirow{2}{*}{75} & \multirow{2}{*}{41} & & \\
\hline & & & $720^{b}$ & $36^{b}$ & & & & \\
\hline & $\begin{array}{l}\text { Lado do } \\
\text { Chanfro }\end{array}$ & Passe & $\begin{array}{l}\text { Corrente } \\
\text { (A) }\end{array}$ & $\begin{array}{c}\text { Tensão } \\
\text { (V) }\end{array}$ & $\begin{array}{c}\text { Velocidade } \\
\text { (cm/min) }\end{array}$ & $\begin{array}{c}\text { Aporte de } \\
\text { Calor }(\mathbf{k J} / \mathrm{cm})\end{array}$ & $\begin{array}{c}\text { Deposição } \\
\text { (kg/h) }\end{array}$ & Geometria \\
\hline \multirow{9}{*}{ 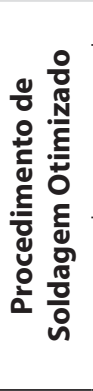 } & Selagem & MAG & 278 & 27 & 34 & 12 & \multirow{5}{*}{25,3} & \\
\hline & \multirow{4}{*}{ Externo } & \multirow{2}{*}{$1^{\circ}$} & $1000^{a}$ & $32^{\mathrm{a}}$ & 45 & 71 & & \\
\hline & & & $800^{b}$ & $34^{\mathrm{b}}$ & 45 & 11 & & Exter \\
\hline & & \multirow{2}{*}{$2^{\circ}$} & $1000^{a}$ & $32^{\mathrm{a}}$ & \multirow{2}{*}{45} & \multirow{2}{*}{71} & & \\
\hline & & & $800^{b}$ & $34^{b}$ & & & & \\
\hline & \multirow{4}{*}{ Interno } & \multirow[t]{2}{*}{$1^{\circ}$} & $950^{\mathrm{a}}$ & $33^{a}$ & \multirow{2}{*}{60} & \multirow{2}{*}{53} & \multirow{4}{*}{25,3} & $E / 2$ \\
\hline & & & $800^{b}$ & $34^{b}$ & & & & Interno \\
\hline & & \multirow{2}{*}{$2^{\circ}$} & $1000^{a}$ & $32^{\mathrm{a}}$ & \multirow{2}{*}{43} & \multirow{2}{*}{87} & & \\
\hline & & & $900^{b}$ & $34^{b}$ & & & & \\
\hline
\end{tabular}

${ }^{a}$ fonte retificadora de corrente contínua. ${ }^{b}$ fonte de corrente alternada de ondas quadrada.

Após a soldagem, realizou-se análise macrográfica de seção transversal à solda, em amostras atacadas com reativo químico nital $4 \%$. Nesta mesma seção, foi realizado o mapeamento de dureza Vickers com carga de $1 \mathrm{kgf}$ e distância entre impressões de $0,35 \mathrm{~mm}$, tanto na direção vertical quanto na horizontal, de forma a evidenciar a variação de dureza provocada pelo ciclo térmico de soldagem. A análise microestrutural das juntas soldadas também foi realizada a partir da seção utilizada na análise macrográfica. Para isto, selecionou-se uma região do lado externo da junta, em que o metal base foi afetado pelo ciclo térmico de um único passe. Foi avaliada, via microscopia ótica (MO) e após ataque químico com reativo nital a 4\%, somente a região de grãos grosseiros (RGG) da zona afetada pelo calor (ZAC).

A microestrutura da ZAC também foi caracterizada em termos de orientação cristalográficas utilizando um microscópio eletrônico de varredura capaz de realizar análise de Difração de Elétrons Retroespalhados EBSD Electron backscatter diffraction. Para tal, as amostras foram preparadas via polimento convencional seguido de polimento mecânico automático em solução contendo pasta de diamante de $0,1 \mu \mathrm{m}$ e sílica coloidal. As análises foram realizadas posicionando as amostras a uma distância de trabalho de $17,5 \mathrm{~mm}$ e com um ângulo de inclinação de $70^{\circ}$ em relação ao feixe de elétrons incidente e $20 \mathrm{kV}$ de tensão.

Os elétrons retroespalhados geram padrões de difração que são capturados por uma tela de fósforo posicionada no interior da câmara de vácuo e transmitidos à uma câmera (fabricante $\mathrm{HKL}$ ) os quais são processados através do software HKL fast acquisition 2007 e comparados com os padrões de raias pré-estabelecidos de Kikuchi (padrão de difração dos elétrons retroespalhados). 
Para cada junta soldada, foram ensaiados 4 corpos de prova (CPs) de tração e 2 CPs de dobramento retirados do lado interno e externo do chanfro. A condição de dobramento utilizada foi de $4 \mathrm{E}-180^{\circ}$, sendo $\mathrm{E}$ a espessura da chapa e 4E o raio de dobramento. Os CPs para estes ensaios foram confeccionados segundo o código ASME, seção IX [10], e ensaiados com base na norma ASTM A370 [11]. Os ensaios de impacto Charpy-V foram realizados em 5 CPs do tipo full size, $(10 \times 10 \times 55) \mathrm{mm}$, retirados a $1 / 4$ da espessura, e ensaiados de acordo com a norma ASTM A370 [11]. Os entalhes foram posicionados no metal de solda (MS), linha de fusão (LF) + $1 \mathrm{~mm}$ e LF + $5 \mathrm{~mm}$, retirados de um dos lados do chanfro. Os CPs do MS e da ZAC foram ensaiados nas temperaturas de -20 e $-30{ }^{\circ} \mathrm{C}$, respectivamente.

\section{Resultados e Discussão}

\subsection{Caracterização metalográfica e mapeamento de dureza das juntas soldadas}

O aspecto macrográfico das juntas soldadas, com os locais onde foram realizadas as análises microestruturais via MO e EBSD, assim como os resultados do ensaio do mapeamento de dureza Vickers são apresentados na Figura 3. É possível observar que os passes de raiz apresentaram boa penetração e as juntas estavam isentas de defeitos, comprovando que os parâmetros de soldagem aplicados foram apropriados.

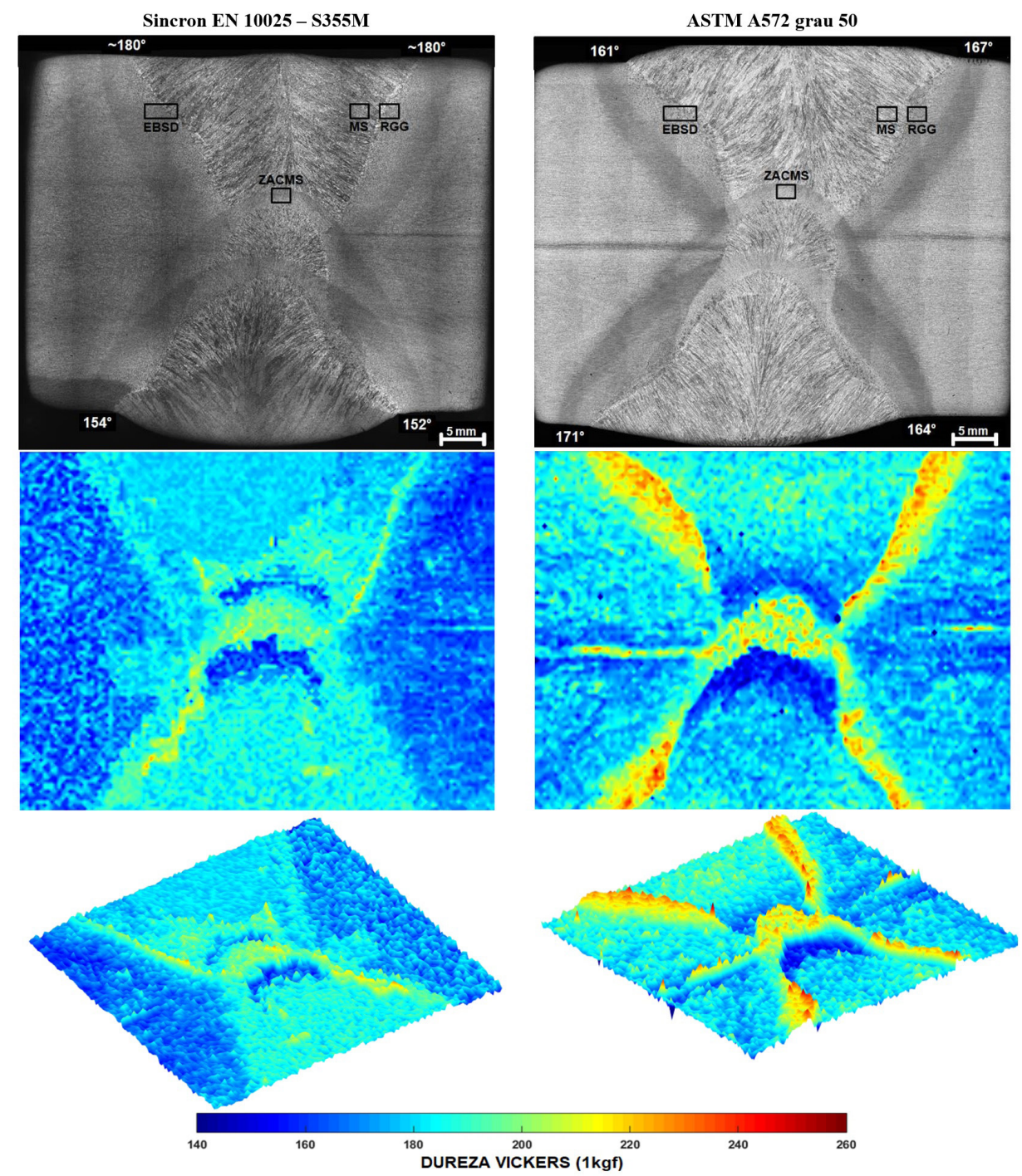

Figura 3. Aspecto macrográfico da região de solda das juntas SAW tandem arc dos aços Sincron S355 M e A572 e mapeamento de dureza Vickers com carga de $1 \mathrm{kgf}$ e distância de 0,35 mm entre impressões. 
Avaliação da Soldabilidade do Aço Sincron EN 10025-4 S355M Aplicado na Fabricação de Torres Eólicas com

Processo de Soldagem de Alta Deposição

O mapeamento de dureza é extremamente útil para estimar as variações de propriedades ao longo da ZAC e do metal de solda (MS), uma vez que os valores de dureza podem ser empiricamente correlacionados com a resistência mecânica e com a susceptibilidade à ocorrência de trincas induzidas localmente por hidrogênio. Observa-se, no caso da junta soldada do aço A572, que o metal de solda apresenta valores de dureza (170 - 210 HV) próximos ao metal base (175 - $212 \mathrm{HV}$ ), indicando que a resistência mecânica da solda é matched (MS com resistência próxima ao MB). Já no caso da junta soldada do aço Sincron S355 M, o metal de solda (178-205HV) é overmatched (MS com resistência superior ao $\mathrm{MB}$ ) em relação ao metal base $(158-178 \mathrm{HV})$.

As regiões de maiores valores de dureza no cordão de solda, tanto para a junta Sincron S355 M quanto para a junta A572, estão localizadas na raiz da solda, a qual foi realizada com eletrodo OK Autrod 12.51, que possui maiores teores de carbono e valores de propriedades mecânicas, Tabela 4, além disso, essa é a região onde sofre uma maior velocidade de resfriamento e qualitativamente uma maior diluição do MS, favorecendo, especialmente para a junta do aço A572, a formação de estruturas de maior dureza. As regiões com menores valores de dureza (140 - 150HV) no cordão de solda das duas juntas avaliadas estão associadas a zonas afetadas pelo calor no cordão de solda (ZACMS) e são referentes aos passes depositados do lado interno do chanfro. Essas regiões amaciadas, claramente evidenciadas na Figura 3, sofreram reaquecimento devido à deposição do passe subsequente do lado externo do chanfro, provocando seu refinamento e revenimento microestrutural. De modo geral, a redução da estrutura bruta de fusão decorrente da solidificação do passe anterior, provoca a queda de dureza e aumenta a tenacidade a baixa temperatura do metal de solda [12].

É possível observar que todos os valores de dureza estão bem abaixo de $350 \mathrm{HV}$, sugerindo que os dois aços avaliados possuem baixa susceptibilidade à ocorrência de trincas a frio induzidas por hidrogênio na ZAC [13-15]. Analisando a Figura 3 é possível evidenciar que a RGG da junta ASTM A572 grau 50 (áreas com tonalidades amarelas e vermelhas da Figura 3) apresentou, praticamente ao longo de toda a sua extensão, com exceção das regiões reaquecidas, valores de dureza muito superiores $(240-260 \mathrm{HV})$ aos valores de dureza do metal base. Já para o aço Sincron S355 M observa-se que essa diferença entre os resultados de dureza da RGG e do MB também existe, porém, não é tão expressiva. O aço $\mathrm{A} 572$ possui maiores valores de carbono e de carbono equivalente e, portanto, é mais sensível aos ciclos térmicos de soldagem utilizados neste trabalho.

O procedimento de soldagem aplicado na fabricação dos tramos metálicos deve levar em conta as condições que favorecem a resistência à fadiga da torre eólica que constantemente sofre solicitações cíclicas. Para isso, não basta somente a aplicação de metal base e consumíveis de solda que possuem elevada resistência mecânica, mas também adotar procedimentos de soldagem que possibilitem a deposição de cordões de solda com geometria ideal, de forma a minimizar a formação de concentradores de tensões, como por exemplo o formato do pé do cordão [16,17]. Segundo a norma ISO 5817:2003 [18], o ângulo do pé do cordão deve ser maior que $150^{\circ}$ que, no caso das juntas deste trabalho, como pode ser visto na Figura 3, atenderam a esse requisito. Caso contrário, recomenda-se seguir as orientações citadas na seção 8.4 da norma AWS D1.1-2010 [19] para modificar o perfil do cordão de solda como, por exemplo, aplicando os métodos de retificação ou de refusão (pelos processos de soldagem a TIG e/ou a plasma).

Na Figura 4 são apresentadas as microestruturas típicas do MS das duas juntas soldadas. A identificação via microscopia ótica (MO) dos diferentes constituintes da zona fundida foi realizada segundo o sistema de classificação do Instituto Internacional de Soldagem (IIW) [20].

De maneira geral, em termos microestruturais, a região MS das duas juntas soldadas apresentou uma microestrutura predominante de ferrita de contorno de grão (FG), perlita (P) e ferrita acicular (FA). Qualitativamente foi observada, para todas as juntas soldadas, uma maior quantidade de FA, com sua típica morfologia de agulhas nucleadas a partir de inclusões [21], em relação aos demais constituintes. Já as regiões do MS que sofreram aquecimento acima da temperatura $\mathrm{Ac}_{1}$ devido ao ciclo térmico do passe de solda subsequente (ZAC-MS), apresentaram um refinamento da estrutura grosseira do MS, formando ferrita equaxial (F) e perlita fina (P) o que, normalmente, melhora a tenacidade dessa região.

A microestrutura do cordão de solda é influenciada pela estrutura primária de solidificação, pelo tamanho de grão da austenita prévia, pela distribuição e tipo de inclusões não metálicas, pelo teor dos diferentes elementos de liga e pelo ciclo térmico de soldagem. A alteração de qualquer uma dessas variáveis afetará as demais, tornando a previsão da microestrutura final do MS complexa quando analisada a influência de apenas um desses fatores [13]. 


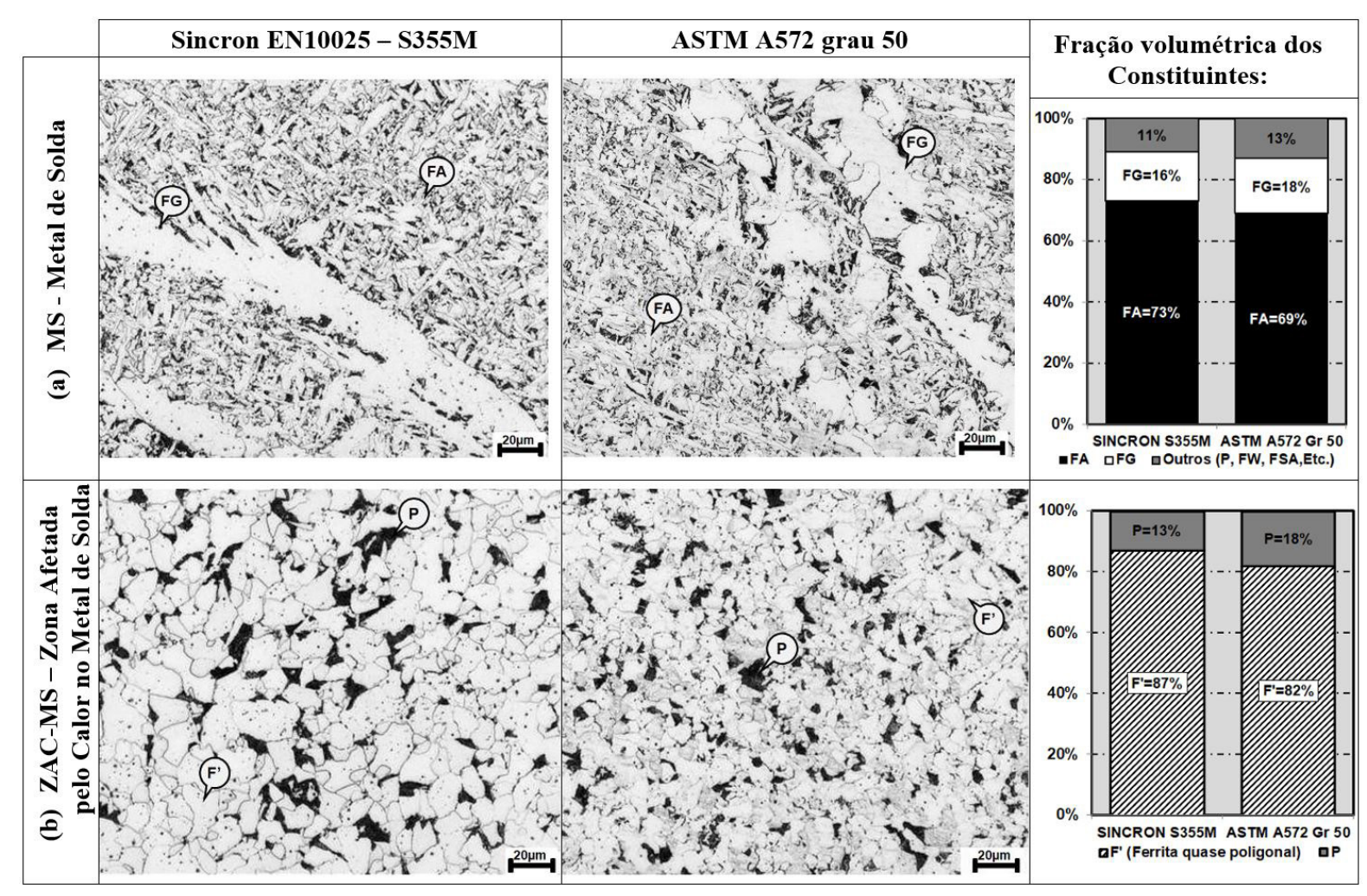

Figura 4. Microestrtura do MS. Ataque nital $4 \%$.

Na Figura 5 são apresentadas as microestruturas identificadas na região de grãos grosseiros (RGG) da ZAC das juntas soldadas avaliadas. Esta análise concentrou-se em regiões que não sofreram reaquecimento em função de ciclo térmico de outros passes de solda conforme indicado na Figura 3. A identificação via $\mathrm{MO}$, dos diferentes constituintes foi realizada segundo o sistema de classificação The Welding Institute (TWI) [22]. Verificou-se nas duas juntas que a microestrutura se apresenta mais grosseira próxima à linha de fusão e à medida que se afasta torna-se mais refinada. De forma geral, observa-se, próximo a linha de fusão, um aumento do grão da austenita prévia devido à alta temperatura de pico atingida nessa região, acima de $1100^{\circ} \mathrm{C}$, e a presença de microestruturas mais grosseiras e de maior temperatura de transformação, favorecidas pela menor velocidade de resfriamento proporcionada pelos aportes térmicos empregados na confecção das juntas em questão.

A análise metalográfica qualitativa ao longo da RGG das duas juntas soldadas revelou diferentes proporções dos mesmos constituintes microestruturais entre os aços avaliados. Na RGG do aço Sincron S355 M observa-se ferrita de contorno de grão (FG) e, em algumas regiões, pequenos nódulos de perlita (P) e ferrita poligonal (FP) nos contornos de grãos da austenita prévia (CGPp), e ferrita com segunda fase alinhada (FSA) e não alinhada (FSN) no interior dos grãos. Já a RGG do aço A572 (Figura 6(a)), é mais extensa, com FG e P nos CGpp, e no seu interior FSA e FSN. É evidente que as microestruturas da RGG do aço Sincron S355 M são mais grosseiras que os constituintes da RGG do aço A572. O aço TMCP, em função de seu menor teor de carbono e valor de carbono equivalente, apresenta o início de transformação em temperaturas mais elevadas que o aço convencional, favorecendo o crescimento e, dessa forma, o alargamento das ripas da ferrita FG, FSA e FSN. No caso do aço A572, devido ao maior teor de carbono, observa-se uma maior quantidade de segunda fase entre as ripas das FSA e FSN, as quais podem ser carbonetos, martensita e martensita/austenita retida (M-A), que tem sua formação favorecida em função das baixas velocidades de resfriamento, o que é o caso da soldagem com elevado aporte de calor. Porém, essa diferenciação só é possível através de análise via microscopia eletrônica de transmissão ou via ataque metalográfico eletrolítico, que não foram realizados neste estudo. Outra diferença significativa entre as RGG dos aços avaliados, principalmente nas Figuras 6(b), é que o tamanho de grão da austenita prévia, que pode ser estimada pela posição das FG, é qualitativamente maior na ZAC dos aços A572 do que na ZAC dos aços Sincron S355 M. O menor tamanho de grão da austenita prévia assim como a menor extensão da RGG dos aços S355M 


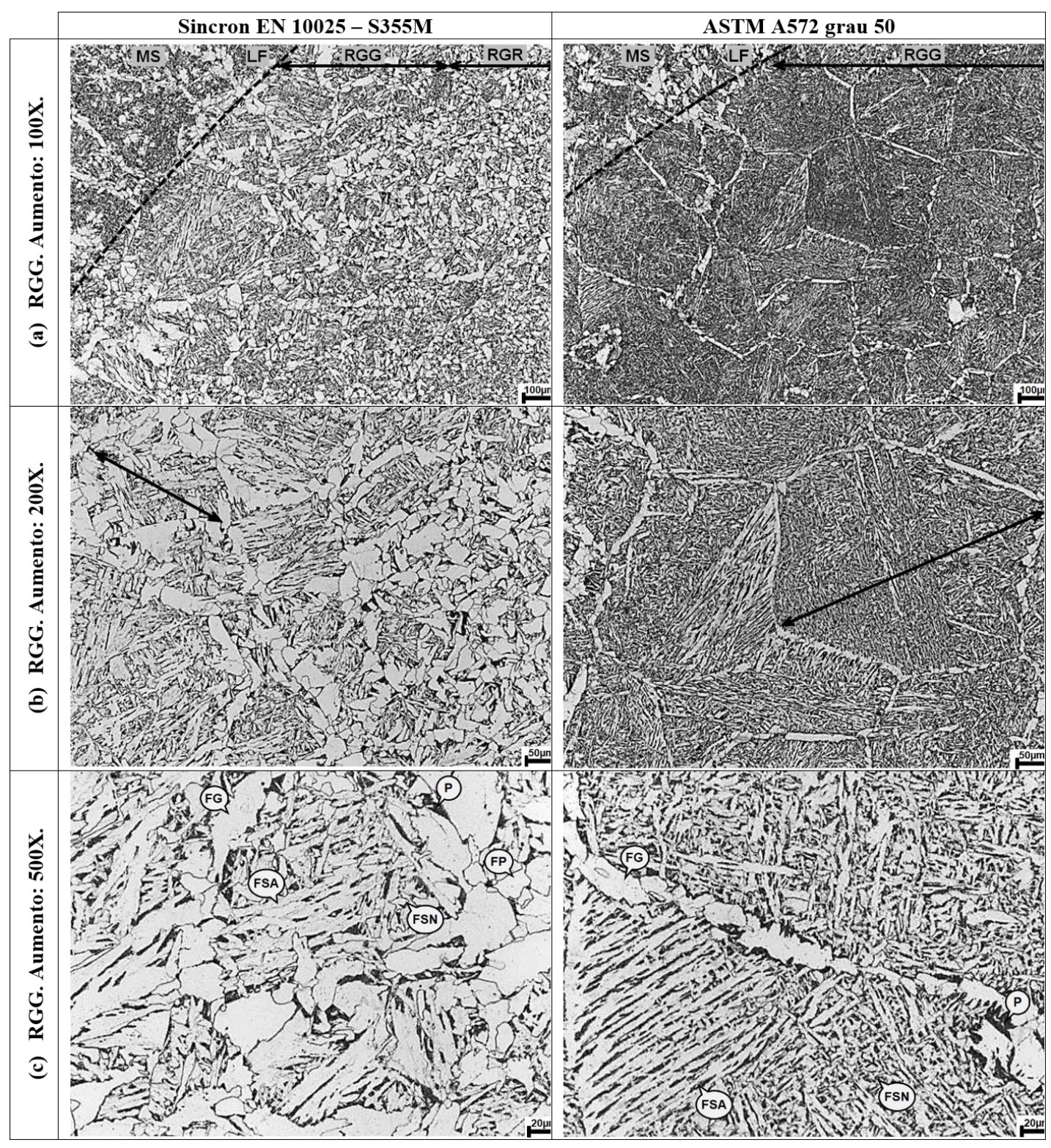

Figura 5. Microestrutura na região de grãos grosseiros (RGG). Ataque nital 4\%. RGR: Região de grãos refinados; MS: Metal de solda; LF: Linha de fusão.
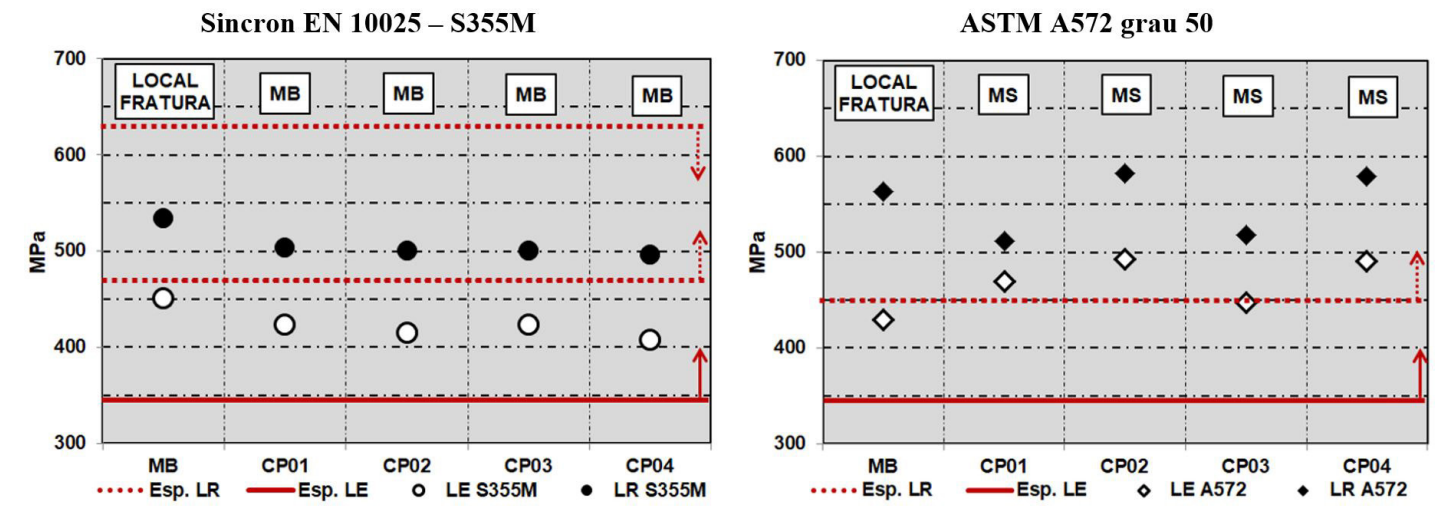

Figura 6. Resultados de tração das juntas soldadas dos aços Sincron S355 M e A572. 
esta associado à presença de precipitados de TiN homogeneamente distribuídos e coerentes com a matriz do $M B$, os quais dificultam a migração dos contornos de grão devido ao efeito pinning [21] em regiões da ZAC onde a temperatura de pico não supere a temperatura de dissolução dos mesmos.

\subsection{Ensaios de tração e de dobramento}

Tanto a junta do aço Sincron S355 M quanto à do aço A572 não apresentaram trincas na região do cordão de solda durante o ensaio de dobramento, comprovando a ausência de defeitos e a boa ductilidade do MS.

Os resultados obtidos nos ensaios de tração das juntas soldadas podem ser observados na Figura 6. A linha vermelha contínua indica o valor especificado para o limite de escoamento (LE) que, para ambos os aços, deve ser maior que $345 \mathrm{MPa}$. Já a linha vermelha pontilhada marca o valor especificado para o limite de resistência (LR) que, para o caso dos aços Sincron EN10025 S355 M, corresponde à faixa de $470 \mathrm{MPa}$ a $630 \mathrm{MPa}$, e para o aço ASTM A572 grau 50 deve ser superior a $450 \mathrm{MPa}$.

O único requisito especificado para as juntas soldadas no ensaio de tração é que o LR atenda ao valor especificado para o metal base [23]. Os valores de limite de escoamento apresentados na Figura 6 são apenas informativos. Esse critério foi atendido para todos os CPs ensaiados, como mostrado na Figura 6. Todas as fraturas ocorreram no MB, no caso da junta soldada do aço Sincron S355 M, e no MS, no caso das juntas soldadas do aço A572.

Uma junta soldada pode ser considerada como sendo um conjunto de diferentes "materiais", MS, ZAC e MB, apresentando uma heterogeneidade mecânica e microestrutural [24] ao longo de sua seção, como já evidenciado no mapeamento de dureza da Figura 3. O efeito da interação das propriedades dessas diferentes regiões nas propriedades de uma estrutura soldada real é difícil de ser mensurado e os CPs tradicionais para qualificação de procedimentos de soldagem não são capazes de evidenciar a interações de tais regiões. Dessa forma, essa heterogeneidade não é considerada no momento do desenvolvimento do projeto de uma estrutura soldada, sendo utilizada, na maioria dos casos, uma abordagem bastante conservadora. Ressalta-se que, nas últimas décadas, vários pesquisadores vêm trabalhando principalmente com uma visão da mecânica da fratura, com diferentes ferramentas como a modelagem computacional e utilização de CPs de diferentes configurações para diferentes tipos de ensaios para tentar determinar o efeito de tal heterogeneidade nas propriedades das juntas soldadas e na integridade de uma estrutura real $[25,26]$.

\subsection{Ensaios de impacto Charpy-V}

Com relação ao ensaio de impacto Charpy das juntas soldadas, os valores de energia absorvida devem satisfazer aos mesmos requisitos especificados para o metal base $\left(34 \mathrm{~J} \mathrm{a}-30^{\circ} \mathrm{C}\right)$. Os resultados obtidos atenderam a esses requisitos, conforme ilustrado na Figura 7.

Todos os resultados, independente do tipo de aço, foram superiores ao mínimo especificado para os materiais avaliados. Todos os CPs com entalhe no MS também foram superiores a 34J. Pode-se dizer que os excelentes valores observados no MS foram em função da maior fração de FA em relação a FG, evidenciado na Figura 4. A ferrita de contorno de grão que é prejudicial à tenacidade a baixas temperaturas por apresentar pacotes grosseiros e contornos de baixo ângulo como será evidenciado na seção 3.4 através da analise via EBSD. Não foram observadas diferenças significativas entre os resultados do MS da junta do aço Sincron S355 M e da junta do aço ASTM A572 grau 50, comprovando que a combinação de consumíveis utilizada é apropriada para ambos os materiais.

Os resultados de ensaio Charpy- $V$ da ZAC, geralmente apresentam uma maior dispersão em função da sua natureza heterogênea [27], principalmente no caso dos CPs amostrados na LF $+1 \mathrm{~mm}$, Figura 7, propiciando a amostragem de diferentes regiões como ZAC, MB e MS ao longo do entalhe de um mesmo CP Charpy, e também devido a pouca agudez do entalhe, sendo um teste pouco sensível às diferentes zonas da ZAC [27]. Segundo Kudoh e Pisarski [28], a energia absorvida em CPs Charpy com uma distribuição heterogênea de microestruturas ao longo do entalhe é dominada pela região de menor tenacidade, quando esta ocupa mais de $30 \%$ do entalhe.

Os maiores valores de tenacidade foram observados para as juntas soldadas do aço Sincron S355 M. Isso se deve principalmente ao menor tamanho de grão da austenita prévia e aos menores teores de carbono e valores de carbono equivalente, que proporcionam a formação de constituintes de menor dureza na ZAC, Figura 3, e a formação de uma menor quantidade de segunda fase dos constituintes FSA e FSN. Segundo a literatura [21,27], FSA e FSN são constituintes frágeis, principalmente quando associados a grandes tamanhos de grãos da austenita 


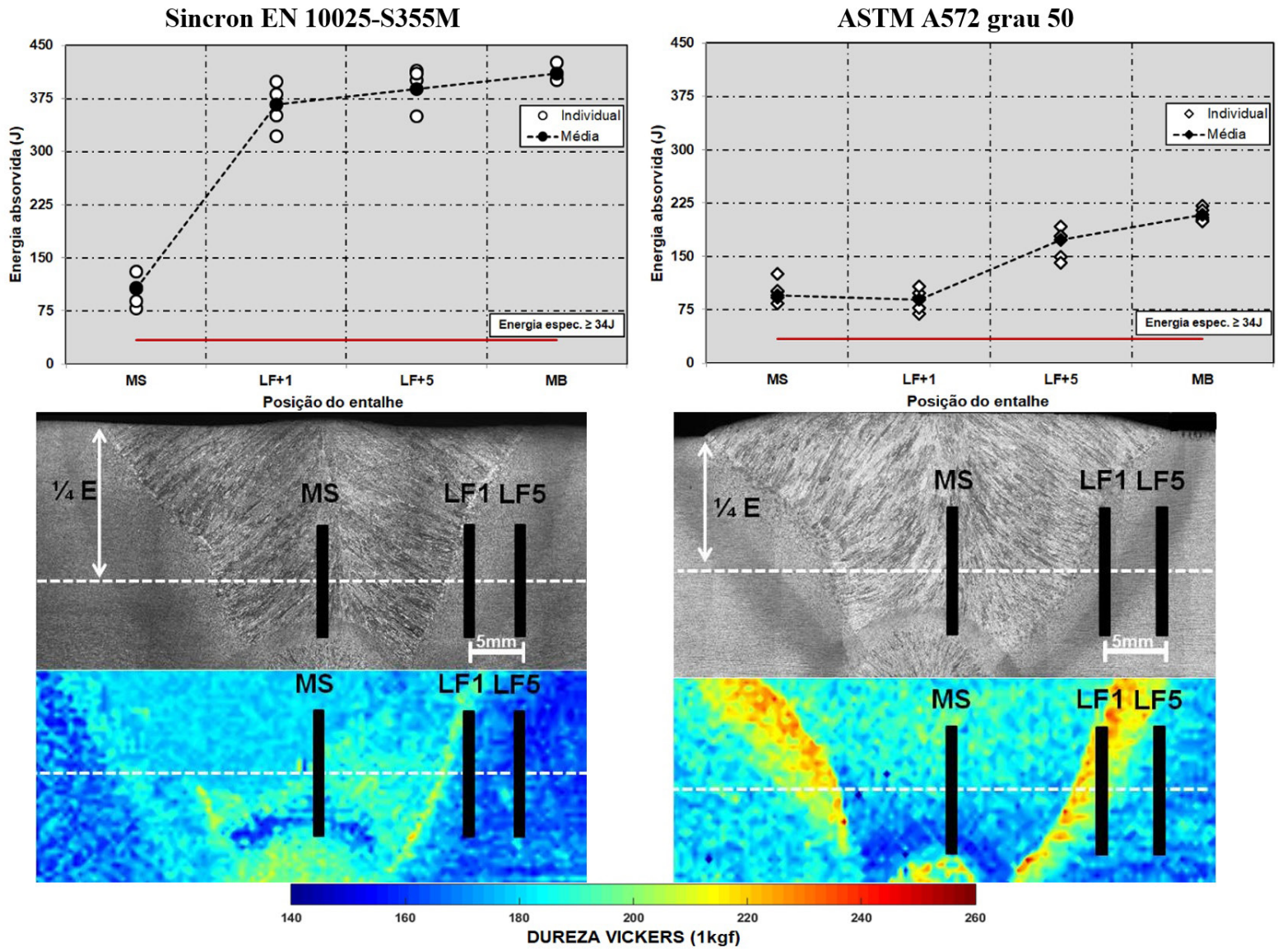

Figura 7. Mapeamento de dureza no local da amostragem dos CPs de impacto Charpy-V e os respectivos resultados de energia absorvidos no $\mathrm{MS}\left(-20^{\circ} \mathrm{C}\right)$ e da ZAC $\left(-30^{\circ} \mathrm{C}\right)$.

prévia, devido aos seus contornos de baixo ângulo e não proporcionam importantes desvios na fratura, gerando facetas de clivagens planas, as quais reduzem a tenacidade do material [14].

\subsection{Características cristalográficas da região soldada}

$\mathrm{O}$ ciclo térmico de soldagem provoca transformações microestruturais complexas no MB resultando em uma heterogeneidade de propriedades mecânicas ao longo da ZAC. As diferentes microestruturas formadas na ZAC geralmente são caracterizadas usando MO devido a sua facilidade de execução. Porém, há certas limitações principalmente quando se deseja correlacionar os constituintes microestruturais com os resultados de tenacidade obtidos com ensaios Charpy-V. A análise via EBSD é uma eficiente técnica para caracterização de microestruturas complexas, especialmente com relação a orientação cristalográfica e desorientação de grãos, informações úteis para entender os mecanismos de falha ao longo da ZAC [29].

Na Figura 8, são apresentadas as imagens dos mapas de orientação próximos a RGG obtidos via EBSD através da varredura de uma área de $2000 \times 450 \mu \mathrm{m}$ usando um passe de análise de 0,9 $\mu \mathrm{m}$. As diferentes cores indicam pacotes de diferentes orientações, os quais são compostos por varias subestruturas microestruturais de mesma orientação cristalográficas. Observa-se que a RGG do aço Sincron S355M é bem menor que a RGG do aço ASTM A572 Gr. 50, já evidenciado na Figura 6, e que está associado ao efeito pinning provocado pelos precipitados de TiN coerentes com a matriz.

Segundo a literatura [30] contornos de grão de alto ângulo, $>45^{\circ}$, são efetivos para dificultar a propagação de microtrincas e, dessa forma, favorecem a tenacidade. Dessa forma, foi realizado analise via EBSD para avaliar os graus de desorientações entre grãos vizinhos em duas áreas de $400 \times 560 \mu \mathrm{m}$ cada, nas regiões onde foram 
amostrados os CPs de Charpy-V LF $+1 \mathrm{~mm}$. A aquisição e o processamento dos dados foram feitas através do software HKL fast acquisition 2007 e as imagens e os histogramas com a distribuição dos ângulos de desorientações foram gerados automaticamente. Os resultados mostrados na Figura 9 evidenciam a natureza heterogênea da

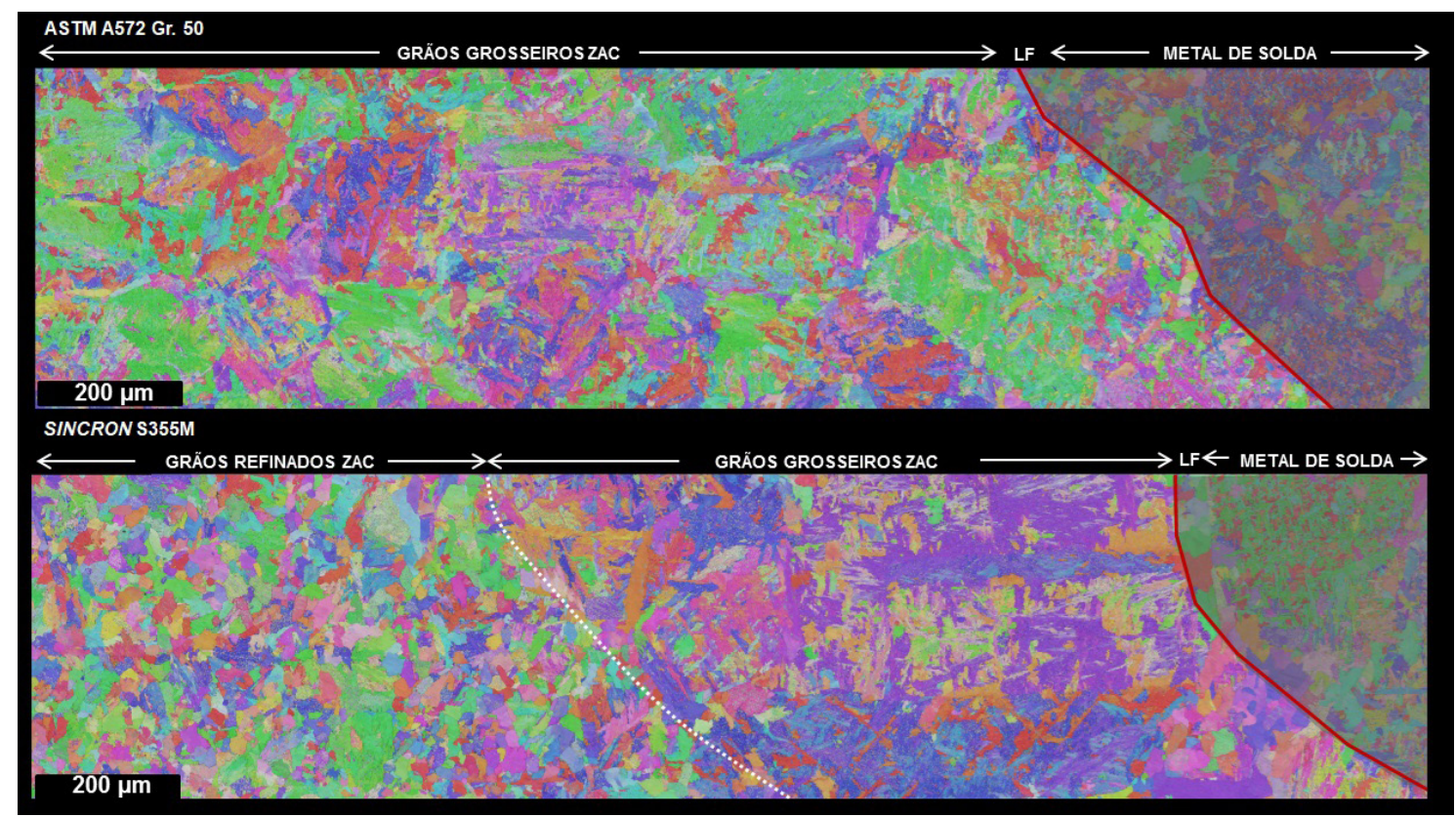

Figura 8. Mapa de orientação cristalográfica da ZAC dos aços avaliados via EBSD.
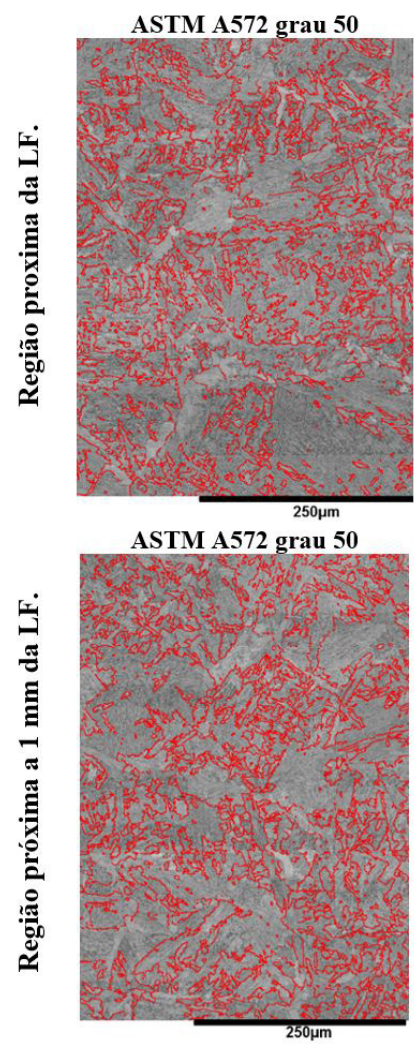
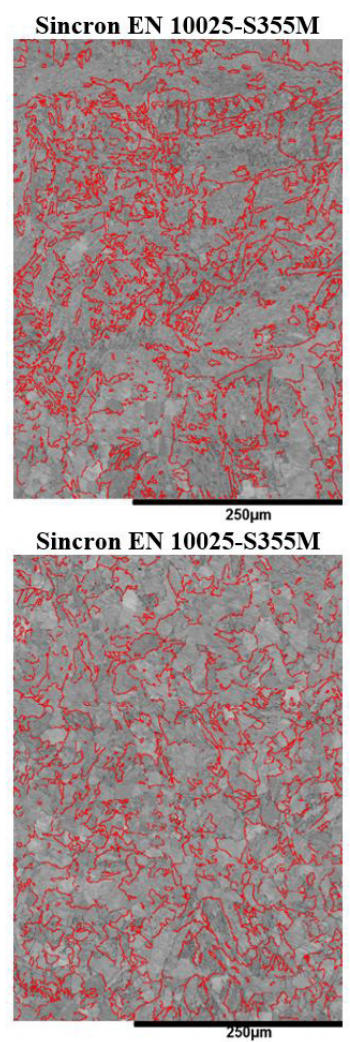
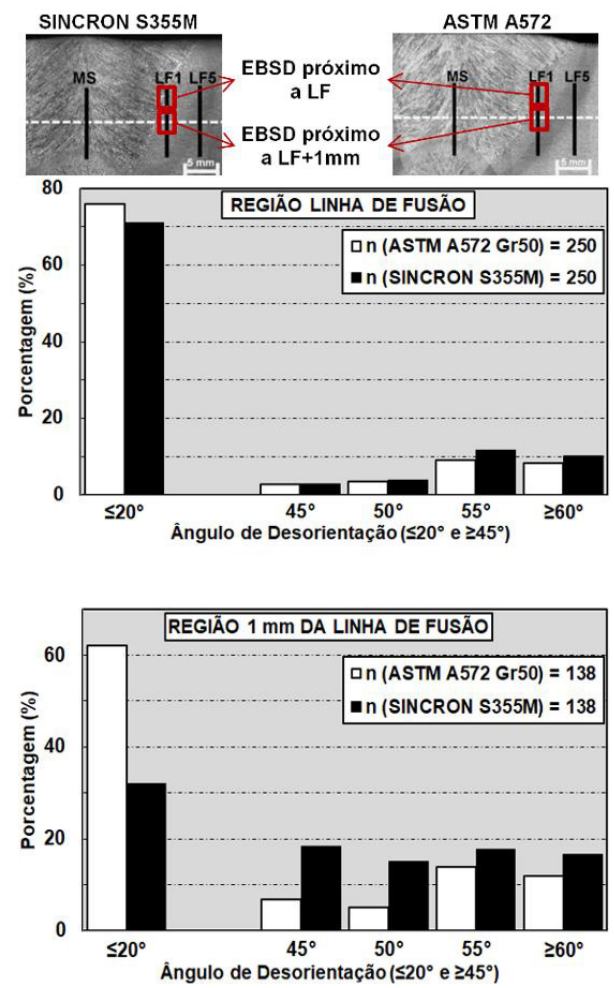

Figura 9. Distribuição do grau de desorientação dos grãos vizinhos na LF $+1 \mathrm{~mm}$ da ZAC dos aços analisados via EBSD. Linha vermelha: Ângulo de desorientação entre grãos vizinhos $\geq a+45^{\circ}$. 
amostragem do entalhe Charpy [27,31], onde próximo a LF, RGG, não há uma diferença significativa entre os dois aços com relação à quantidade de grãos de alto ângulo, $>45^{\circ}$. Porém, a $1 \mathrm{~mm}$ da LF, a ZAC do aço Sincron S355M apresenta uma quantidade superior de grãos com subestruturas de alto ângulo em relação a ZAC do aço A572, o qual possui cerca de $60 \%$ de grãos compostos, na sua maioria, por pacotes grosseiros de FSA com subestruturas paralelas e de baixo ângulo de desorientação, $<20$ 으, considerados, prejudiciais a tenacidade desse material. $\mathrm{Na}$ Figura 10 e 11 são mostrados os perfis de desorientação, no sentido das setas pretas, no interior da FSN (Sincron S355M) e FSA (A572) na RGG, e na FA e FG do MS, respectivamente. Observa-se que as subestruturas internas da FSN (RGG Sincron S355M) e da FA (MS) são próximas uma das outras e a maioria dos contornos é de alto ângulo com desorientação superior a $45^{\circ}$ o que confere uma excelente combinação entre resistência e tenacidade. Já a FSA (A572) e a FG (MS) são compostas por subestruturas grosseiras e de baixo ângulo prejudicando a tenacidade dessa região [31].

Outro fator que pode ter contribuído para os melhores resultados de tenacidade das juntas Sincron S355 M em relação ao aço A572 é a menor susceptibilidade à formação de microfases frágeis como a M-A [21], entre as placas de ferrita dos constituintes FSA e FSN, devido ao seu menor teor de carbono. Segundo Ikawa et al. [32] e Komizo e Fukado [33], materiais com maiores teores de carbono quando soldados com maiores aportes térmicos possuem uma maior tendência à formação de constituintes frágeis do tipo M-A como pode ser observado na Figura 12, onde a RGG do material A572 apresenta uma quantidade considerável de M-A em relação à ZAC do aço Sincron S355M. A presença de microfases M-A entre as placas de ferrita são pontos favoráveis para a nucleação de trincas, reduzindo a tensão de fratura do material e, dessa forma, facilitando a propagação instável da fratura [21,32,33] na ZAC, mesmo se essa apresentar quantidade considerável de contornos de grãos superiores a $45^{\circ}$.
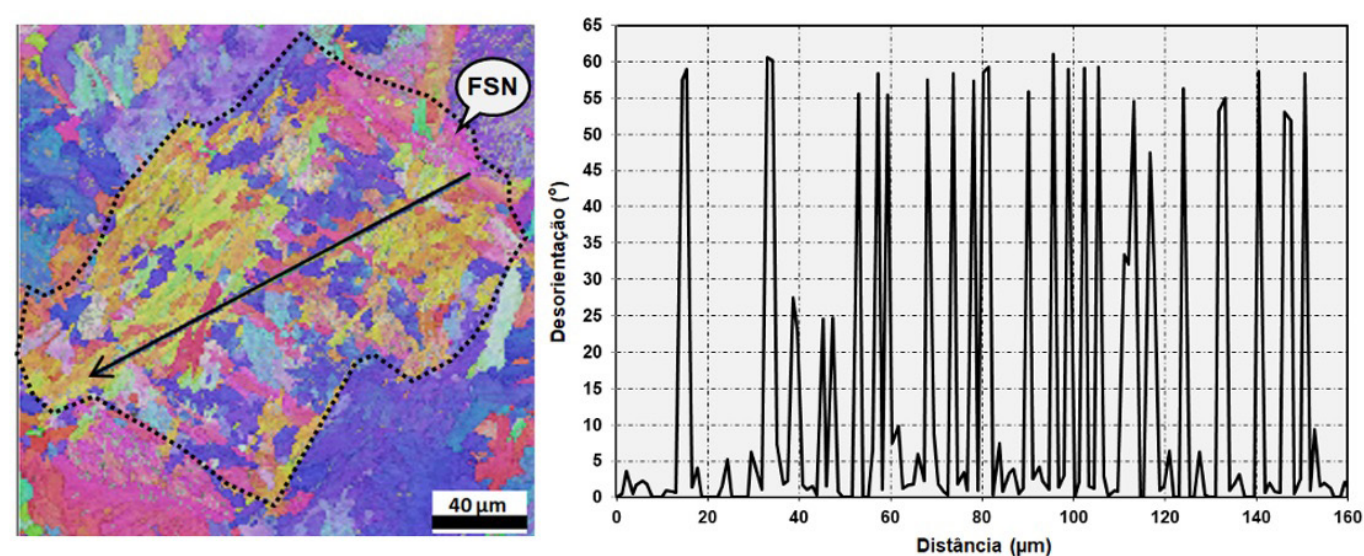

(a) FSN da RGG do aço Sincron S355M.
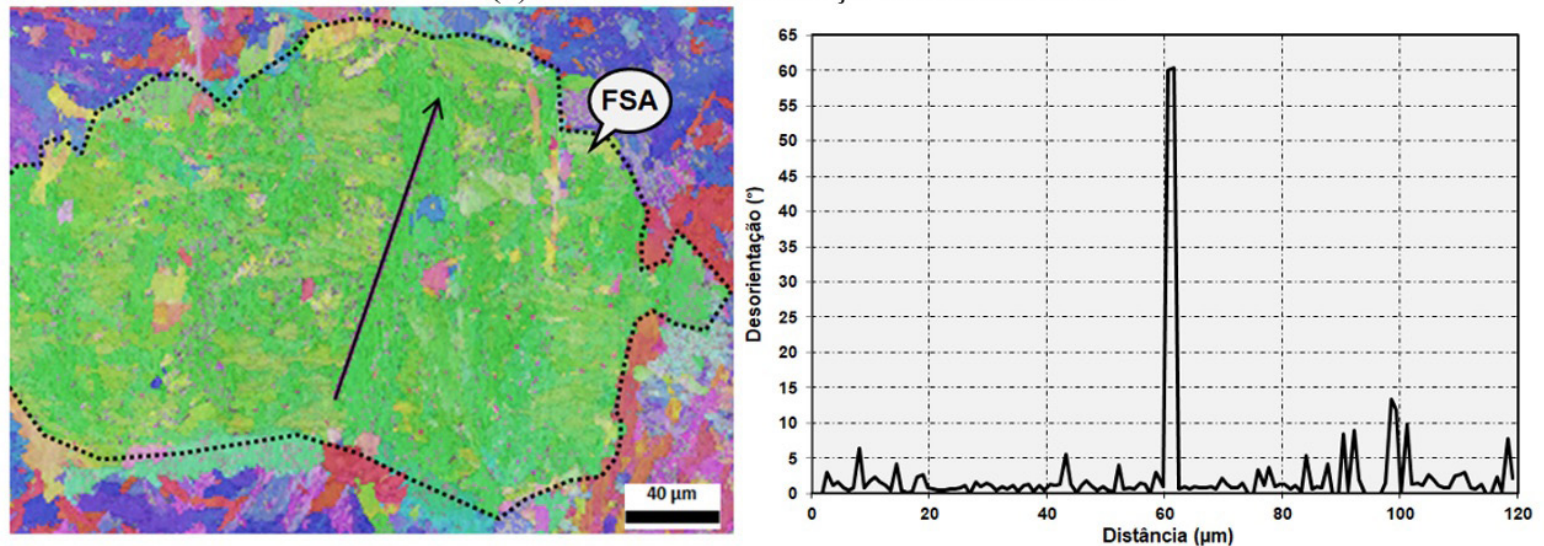

(b) FSA da RGG do aço ASTM A572.

Figura 10. Mapa cristalográfico e perfil de desorientação no sentido da seta no interior dos constituintes FSN (a) e FSA (b) da RGG dos aços Sincron S355M e ASTM A572, respectivamente. 

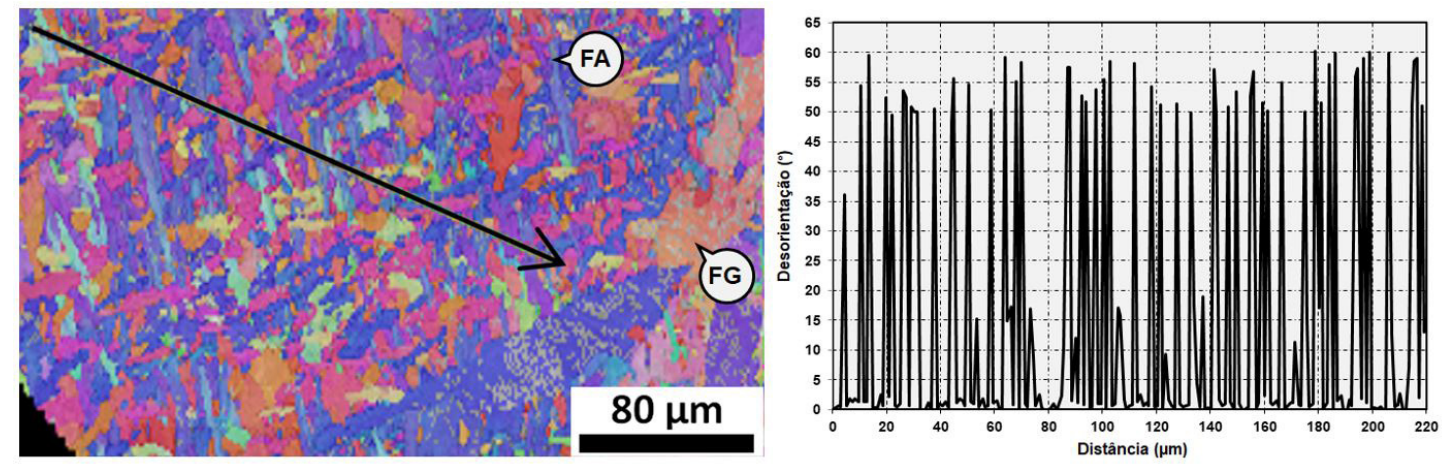

(a) FA no MS.
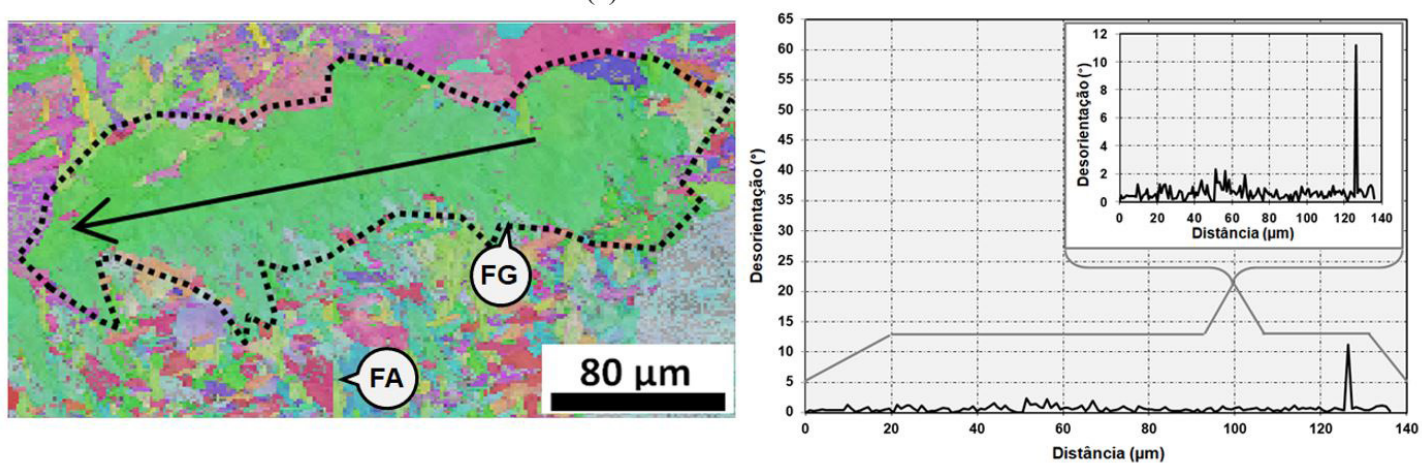

(b) FG no MS

Figura 11. Mapa cristalográfico e perfil de desorientação no sentido da seta no interior dos constituintes FA (a) e FG (b) do MS da junta soldada do aço ASTM A572.

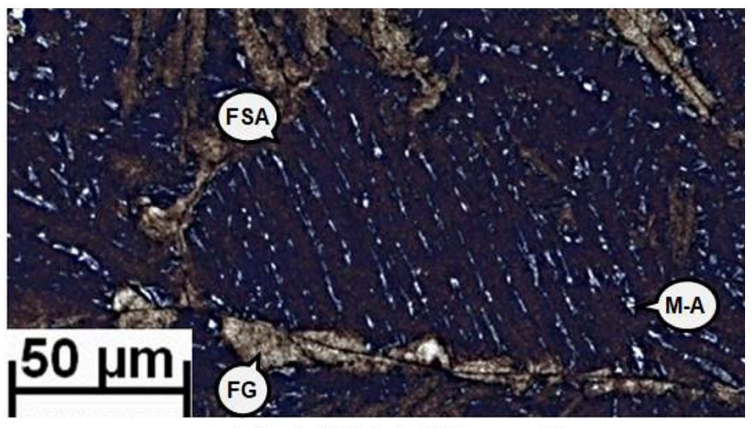

(a) ASTM A572 grau 50.

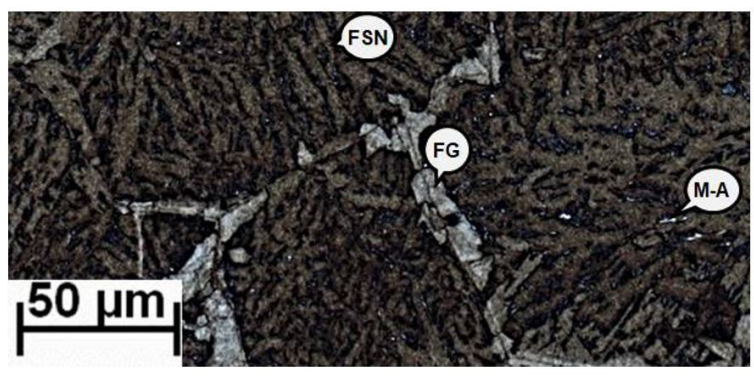

(b) Sincron EN 10025-S355M.

Figura 12. Análise metalográfica evidenciando microfase M-A na RGG do aço ASTM A572 (a) e sua ausência na RGG do aço Sincron S355M (b). Ataque: picral + metabissulfito de sódio.

\section{Conclusões}

Neste trabalho foi avaliado o desempenho dos aços estruturais Sincron S355M e ASTM A572, quando soldados pelo processo SAW Tandem Arc empregando elevado aporte de calor. Os resultados dos ensaios mecânicos e das caracterizações microestruturais realizadas na região soldada permitiram concluir que:

- Macrografia e ensaios mecânicos: (i) todas as juntas soldadas apresentaram-se isentas de defeito; (ii) o aspecto geométrico dos cordões de solda foi favorável para aplicações com carregamento cíclicos; (iii) não foi observado trincas no ensaio de dobramento e; (iv) todos os CPs de tração apresentaram limite de resistência superior aos valores especificados para os MBs. Todos esses resultados ratificando que o procedimento de soldagem empregado está adequado para a fabricação dos tramos metálicos; 
Avaliação da Soldabilidade do Aço Sincron EN 10025-4 S355M Aplicado na Fabricação de Torres Eólicas com

Processo de Soldagem de Alta Deposição

- Mapeamento de dureza Vickers: (i) as duas juntas soldadas apresentaram valores inferiores a 350 HV, indicando baixa susceptibilidade à formação de trincas induzidas pelo hidrogênio nas condições avaliadas neste estudo; (ii) os maiores valores de dureza foram observados ao longo de toda a RGG da ZAC do aço ASTM A572 grau 50; (iii) o MS das duas juntas apresentaram maiores valores de dureza na região da raiz devido a maior velocidade de resfriamento dessa região e a utilização do consumível ER70S-6 de maior resistência no passe de selagem;

- Tenacidade Charpy-V: (i) os valores de energia absorvida no ensaio de impacto Charpy-V, independente do tipo de aço e da região da solda avaliada, ficaram acima do mínimo especificado para os metais base; (ii) o MS dos dois aços em questão, apresentaram excelentes valores de tenacidade sendo justificado pela presença de uma maior fração de FA em relação a FG; (iii) os melhores resultados de tenacidade foram obtidos para o aço Sincron S355 M que, próximo a $1 \mathrm{~mm}$ da linha de fusão, apresentou valores da ordem de $370 \mathrm{~J}$, superiores ao valor médio, 89 J, obtido nessa mesma região da junta soldada do aço ASTM A572; (iv) o menor teor de carbono e os menores valores de carbono equivalente, a menor tendência de formação de de microfases frágeis como a M-A e, principalmente, o menor tamanho de grão da austenita prévia da região de grãos grosseiras, e a maior quantidade de estruturas com contornos de grão de alto ângulo, foram os principais fatores para a maior tenacidade do aço Sincron S355 M;

- Análise Cristalográfica: a utilização da análise via EBSD demonstrou ser uma excelente ferramenta para auxiliar na caracterização e diferenciação das complexas microestruturas formadas na ZAC e sua influencia nas propriedades finais das juntas soldadas.

Pode-se concluir que a utilização da combinação aço Sincron S355 M com o fluxo/eletrodo AWS A5.17 F7A8-EM12K em conjunto com o procedimento de soldagem SAW Tandem Arc otimizado apresentado neste trabalho pode ser uma excelente opção para o aumento da produtividade dos fabricantes de torres, podendo reduzir de nove para quatro, o número de passes, aumentando a taxa de deposição média de 20 para $25 \mathrm{~kg} / \mathrm{h}$ nas soldas longitudinal e circunferencial dos tramos metálicos.

\section{Referências}

[1] Ministério de Minas e Energia. Programa de incentivo as fontes alternativas de energia elétrica [página da internet]. Brasília: MME; 2016 [acesso em 16 ago. 2016]. Disponível em: http:// www.mme.gov.br/programas/proinfa

[2] Associação Brasileira de Energia Eólica. [página da internet]. São Paulo: ABEEólica; 2016 [acesso em 16 ago. 2016]. Disponível em: http://www.portalabeeolica.org.br

[3] Elektriska Svetsnings Aktie Bolaget. Efficient welding in the wind tower manufacturing industry [página da internet]. Contagem: ESAB; 2016. [acesso em 16 abr. 2016]. Disponível em: http:// www.esabna.com/us/en/products/index.cfm?fuseaction=home. product\&productCode $=971 \&$ tab $=2$

[4] Agência Brasileira de Desenvolvimento Industrial. Mapeamento da cadeira produtiva da indústria eólica no Brasil [página da internet]. São Paulo: ABDI; 2014 [acesso em 16 ago. 2014]. Disponível em: http://investimentos.mdic.gov.br/public/ arquivo/arq1410360044.pdf

[5] Meester B. Note on the carbon equivalent. Welding in the World. 1990;28(3/4):8-11.

[6] Hall EO. The deformation and ageing of mild steel: III discussion of results. Proceedings of the Physical Society. 1951; 64(9): 747-753.

[7] Armstrong RW. 60 years of hall: past to present nano-scale connections. Materials Transactions. 2014;55(1):2-12.

[8] Kong X, Liangyun L. Optimization of mechanical properties of high strength bainitic steel using thermo-mechanical and accelerated cooling process. Journal of Materials Processing Technology. 2015; 217: 202-210.

[9] Elektriska Svetsnings Aktie Bolaget. Catálogo on-line [página da internet]. Contagem: ESAB; 2016 [acesso em 26 ago. 2016]. Disponivel em: http://www.esabna.com/us/en/index.cfm

[10] The American Society of Mechanical Engineers. Boiler and pressure vessel Code IX: qualification standard for welding and brazing procedures, welders, brazers, and welding and brazing operators. New York: ASME; 2010.

[11] American Society for Testing And Materials. ASTM A370: standard test methods and definitions for mechanical testing of steel products. West Conshohocken: ASTM; 2009.

[12] Easterling K. Introduction to the physical metallurgy of welding. Londres: BMM; 1983. $231 \mathrm{p}$.

[13] Kawano H. Fatigue strength of thermo-mechanically controlled process steel and it's weld joint. In: Proceedings of The 12nd International Offshore and Polar Engineering Conference; 2001; Kitakyushu. EUA: IOPEC; 2002. p. 368-375.

[14] Alé RM, Torres JAO, Turani LO. Soldagem de aços de alta resistência produzidos via resfriamento acelerado. In: Anais do $65^{\circ}$ Congresso Internacional da Associação Brasileira de Metalurgia, Materiais e Mineração; 2010 Julho 26-30; Rio de Janeiro. São Paulo: ABM, 2010.

[15] Meester B. The weldability of modern structural tmcp steel. ISIJ International. 1997;37(6):537-551.

[16] Zhang YH, Maddox S. Fatigue testing of full scale girth welded pipes under variable amplitude loading. In: Proceedings of The Annual Conference on Ocean, Offshore and Arctic Engineering; 2012 July 1-6; Rio de Janeiro. New York: ASME; 2012. 83054.

[17] Pollard B, Cover J. Fatigue of steel weldments. Welding Research Supplement. 1972;544-554. 
[18] International Organization For Standardization. EN ISO 5817: welding - fusion-welded joints in steel, nickel, titanium and their alloys - quality levels for imperfections. United Kingdom: ISO; 2003.

[19] American Welding Society. AWS D1.1/D1.1M: structural welding code-steel. Miami: AWS; 2010.

[20] International Institute Of Welding. IIW doc. n. IX - 1533-88: guide to the light microscope examination of ferritic steel weld metals. Roissy-en-France: IIW; 1988. 20 p.

[21] ALÉ, R. M. Efeito da Adição de Elementos de Liga (Cu e Ni) nas Propriedades Mecânicas e Microestrutura da ZAC de Aços C-Mn Microligados ao Nb [tese de doutorado]. Rio de Janeiro: COPPE, UFRJ; 1994.

[22] The Welding Institute. Introductory notes on metallography of welds in C-Mn steels. United Kingdom: The Welding Institute; 1984. $36 \mathrm{p}$.

[23] American Welding Society. Welding handbook: welding technology. 8th ed. Miami: AWS; 1987. 638 p.

[24] Hertelé S, Gubeljak N, Waele W. Advanced characterization of heterogeneous arc welds using micro tensile test and two-stage strain hardening ('ugent') model. International Journal of Pressure Vessels and Piping. 2014;119:87-94.

[25] Lee MMK, Luxmoore AR, Cray MJ. A finite element study of short cracks in mis-matched double ' $V$ ' welds. In: Proceedings Of The International Symposium On Mis-Matching Of Welds; 1993; England. England: Mechanical Engineering Publications; 1993. p. 641-660.
[26] Zhang ZL, Thaulow C, Hauge M. Effects of crack size and weld metal mismatch on the haz cleavage toughness of wide plates. Engineering Fracture Mechanics. 1997;57(6):653-664.

[27] Batte AD, Kirkwood PR. Developments in the weldability and toughness of steels for offshore structure. In: Proceedings of The 88th International Conference on Microalloying; 1988 September 24-30; Chicago. USA: ASME; 1988. p. 175-188.

[28] Pisarski, H.G. e Kudoh, J. Exploratory studies on the fracture toughness of multipass welds. In: Proceedings of The 87th International Symposium On Welding Metallurgy Of Structural Steels; 1987 February 22-26; Denver. USA: AIME; 1987. p. 269-277.

[29] Lee SG, Lee DH, Sohn SS, Lee S. Effect of Ni and Mn addition on critical crack tip opening displacement (CTOD) of weld-simulated heat affected zones of three high-strength low alloy (HSLA) steels. Materials Science \& Engineering A. 2017; 55-65.

[30] Gourgues AF, Flower HM, Lindley TC. EBSD study of acicular ferrite, bainita and martensitic steel. Materials Science and Technology. 2000; 16:26-40.

[31] Borba TMD, Flores WD, Turani LO, Cardoso R Jr. Assessment of the weldability of EH36 TMCP shipbuilding steel welded by high heat input submerged arc welding. Welding International. 2016; 31(3): 184-195. https://doi.org/10.1080/09507116.2016 .1218619 .

[32] Ikawa $\mathrm{H}$, Oshige $\mathrm{H}$, Tanoue $\mathrm{T}$. Effect of MA constituent on HAZ toughness of a high strength steel. Journal of the Japan Welding Society. 1980;49(8):532-537.

[33] Komizo YI, Fukado Y. CTOD properties and MA constituent in HAZ of C-Mn microalloyed steel. Quarterly Journal of the Japan Welding Society. 1986;4(2):447-452. 